\title{
Advantages of a two-step procedure for the screening of idiopatic scoliosis
}

\author{
Angelo Gabriele Aulisa1, Marco Galli*2, C Perisano ${ }^{2}$ and L Aulisa ${ }^{2}$
}

Address: ${ }^{1}$ Department of Orthopedics, Pediatric Hospital Bambino Gesù, Rome, Italy and ${ }^{2}$ Department of Orthopedics, A. Gemelli University Hospital, Rome, Italy

* Corresponding author

from $5^{\text {th }}$ International Conference on Conservative Management of Spinal Deformities

Athens, Greece. 3-5 April 2008

Published: 15 January 2009

Scoliosis 2009, 4(Suppl I):O5 doi:I0.II86/I748-7|6I-4-SI-O5

This abstract is available from: http://www.scoliosisjournal.com/content/4/SI/O5

(c) 2009 Aulisa et al; licensee BioMed Central Ltd.

\section{Background}

To verify if our two step modality of scoliosis screening on 8995 children (age 9-14) does diminish the radiological exposure. The result will assist in an estimated reduced rate of radiogenic fatal cancers and lower the social economic burden.

\section{Materials and methods}

Two different methodologies were used. In a first group (n. 5731: group A), the first clinical examination was performed by the school physicians. Doubtful cases were referred by the physician to the Orthopaedic specialist. In a second group (n. 3264: group B), the clinical examination was directly performed by the orthopaedists. Either for the first group or for the second, the specialist ascertained by X-rays the suspected scoliosis and deferred to a 6 month control for the still doubtful cases. To evaluate the lifetime attributable risk of cancer mortality, we have followed the ICRP 60 . To calculate the social economic burde, we have assumed the present reimbursement to the Hospitals by the National Health Service which is Euro 70 for each examination.

The statistic significance of the differences was assessed by the $\mathrm{z}$ test for proportions.

\section{Results}

In group $\mathrm{A}, \mathrm{n} .86 \mathrm{Rx}$ examinations were performed on 5731 children $(1.5 \%)$ and in group B n. 95 on 3266 subjects $(2.91 \%)\left(\mathrm{z}=4.452, \mathrm{p}<10^{-3}\right)$. The screening of 1000 children implies a collective dose $\mathrm{E}$ of $0.65+0.98=1.63$ Sv (boys) or $1.21+1.2=2.41 \mathrm{~Sv}$ (girls).

The risk of a fatal tumour for each examination in males is $4.075(1.63 \times 2.5): 20000$. A screening on 10000 children directly examined by the specialist would require 291 Rx examinations $(2.91 \%)$, while by the two-step procedure they would be reduced to $150(1.5 \%)$, with a saving of $70 \times 141=980$ Euro and of $0.283 \mathrm{~Sv}$ of collective dose.

The number of the Rx examinations halved (141 instead of 291) by the two-step procedure, and the number of malignant tumours due to radiations halved.

\section{Conclusion}

The comparison of the two methodologies shows that the "two steps" procedure reduces the social economical burden, but its main advantage appears on the radioprotection side, which is particularly important in children.

\section{References}

I. Health risks from exposures to low levels of ionizing radiations: BEIR VIIPhase 2 National Academic Press, USA; 2006.

2. United Nations Scientific Committee on the Effects of atomic Radiation (UNSCEAR): Report 2000 to the General Assembly, Volumes I and II. United Nations, New York; 2000.

3. Hansen J, Jurik AG, Firgaard B, Egund L: Optimization of scoliosis examinations in children. Pediatr Radiol 2003, 33:752-65. 